\title{
Psicopatologia nas histórias em quadrinhos e cartoons
}

\section{Psychopathology in newspaper cartoons and comic strips}

\author{
Tomás Moraes Abreu Bonomi ${ }^{1}$, Francisco Lotufo Neto 2 \\ 1 Pontifícia Universidade Católica de São Paulo (PUC-SP). \\ 2 Departamento de Psiquiatria da Faculdade de Medicina da Universidade de São Paulo (FMUSP).
}

Recebido: 19/3/2010 - Aceito: 11/8/2010

\begin{abstract}
Resumo
Objetivo: Este artigo classifica e analisa a forma e a frequência com a qual uma amostra de histórias em quadrinhos brasileiras e norte-americanas retrata a psicopatologia. Além disso, compara a frequência dos temas saúde, saúde mental, psicopatologia geral e especial entre essas tiras. Método: Foi coletada uma amostra de 1.883 tirinhas publicadas pelos jornais Folha de São Paulo e New York Times, no período de 1/2/2007 a 31/7/07. Nessa amostra, 1.022 tiras são de seis autores nacionais e 293, de autores norte-americanos, publicados pela Folha de São Paulo, e 568 publicados pelo New York Times. Foram criadas categorias para classificá-las. Resultados: Entre os autores nacionais, 75,3\% das tiras contêm temas relacionados à área da saúde. Tal categoria se divide em: saúde física, $12,9 \%$, e saúde mental, $62,4 \%$. Por outro lado, os autores americanos registram a temática da saúde em $39,2 \%$ das tiras. Sua preferência é pela crítica de costumes e temas políticos, principalmente a guerra. Quando saúde foi apresentada, os temas foram obesidade e ausência de cuidados adequados aos veteranos de guerra. Conclusões: As histórias em quadrinhos mostram que violência, pobreza e principalmente saúde são temas muito representados pelos autores brasileiros. Já os quadrinhos americanos abordam principalmente a temática da crítica aos costumes. O tema psicopatologia geral é amplamente utilizado como recurso para criar situações de humor. Os temas de psicopatologia são semelhantes no Brasil e nos Estados Unidos. As histórias brasileiras cobrem variedade maior de problemas de saúde física. Por meio do humor, os quadrinhos chamam atenção para os problemas de nossas sociedades.
\end{abstract}

Bonomi TMA, Lotufo Neto F / Rev Psiq Clín. 2010;37(6):291-5

Palavras-chave: Histórias em quadrinhos, cartoons, saúde, psicopatologia, psiquiatria, sexualidade.

\begin{abstract}
Objective: This paper classifies and analyzes how and with what frequency psychopathology is portrayed in a sample of Brazilian and American cartoons and comic strips. It compares the frequency in which health issues, mental health, special and general psychopathology are addressed. Method: A sample of 1,883 cartoons and comic strips published in a six month period by the newspaper Folha de São Paulo and the New York Times was collected from February first to July 31 of 2007. Thousand and twenty-two strips were by Brazilian authors, 293 by American authors published by Folha de São Paulo and 568 by the New York Times. Categories were created to classify them. Results: Among Brazilian authors, $75.3 \%$ of the strips deal with health related themes. This category is divided into: physical health (12.9\%) and mental health (62.4\%). On the other hand, the American authors seldom address the theme health. Their preference was to social customs and habits and political issues, specially related to war. When health was presented the issues were mainly related to obesity and the lack of adequate care to the war veterans. Discussion: Comic books and strips show that violence, poverty and especially health are major concerns of the Brazilians comics authors, whereas the American comics and cartoons deal mainly with election politics and the war. The Brazilian stories address the topic of mental health more frequently, yet the portrayed psychopathological signs and symptoms are basically the same as Americans. Brazilian stories also cover a greater variety of topics related to physical health. The American ones deal mostly with obesity related themes. Through humor, the comics call attention to the problems of our societies. In Brazil especially those of mental health and in United States the Iraq and Afghanistan war.
\end{abstract}

Bonomi TMA, Lotufo Neto F / Rev Psiq Clín. 2010;37(6):291-5

Keywords: Comics, comic strips, cartoons, health, psychopathology, psychiatry, sexuality.

\section{Introdução}

História em quadrinhos no Brasil (e história aos quadradinhos em Portugal) é uma forma de arte que combina imagem e texto e que, por meio do encadeamento de quadros, narra uma história ou ilustra uma situação. Entre as imagens há um corte gráfico que delimita a noção de espaço e tempo. A história em quadrinhos carece de movimento, mas o sugere. É o leitor que lhe dá movimento e continuidade em sua imaginação ${ }^{1}$.

O tema principal dos quadrinhos é o humor, por essa razão os norte-americanos intitulam suas histórias em quadrinhos de comic books. A palavra "comic", em inglês, significa fazer rir a partir de cenas e problemas da vida cotidiana. Além da temática do humor, existem quadrinhos realistas, literários, dramáticos, fantásticos e educativos.

Silva $^{2}$ mostra que nos quadrinhos se observa a utilização de dois códigos: o de imagens e o linguístico. Em relação às imagens, observam-se as ambiências criadas pelas cores, sombras e enquadramentos, que informam sobre as características dos personagens e o desenvolvimento da ação. Do ponto de vista linguístico, os balões são o espaço em que a fala ou os pensamentos dos personagens são inseridos. O uso dos balões delimita a diferença entre quadrinhos e qualquer outra forma de narrativa ${ }^{2}$.

Algumas ferramentas linguísticas foram criadas para superar a falta de som. O tamanho das letras, os tipos de balóes, as palavras, os sinais e as onomatopeias indicam a intensidade da voz e reproduzem sons, ruídos e ideias. Isso permite que os leitores possam "escutar" sem que nenhum som seja emitido ${ }^{1}$.

Segundo Dalgalarrondo ${ }^{3}$, psicopatologia é a ciência que estuda os transtornos mentais e comportamentos anormais e investiga os fenômenos psíquicos patológicos conscientes que ocorrem nos seres humanos. Ela se divide em geral e especial. Psicopatologia geral é o estudo sistematizado dos sinais e sintomas que indicam presença de transtorno mental. Ela divide o psiquismo humano em conceitos 
operativos (funções psíquicas) para depois agrupá-los em quadros nosológicos que serão estudados pela psicopatologia especial. Esta trabalha principalmente com síndromes, conjuntos de sintomas com causas diversas, características das diversas formas de adoecer ${ }^{3}$.

Foi realizada revisão bibliográfica utilizando as palavras "comics", "comic strip", "cartoon", "psychiatry", "psychopathology" e "psychotherapy", nos bancos de dados PubMed e Psychlit. No Lilacs e na SciELO, usaram-se os termos "história em quadrinhos", "quadrinhos", "psiquiatria", "psicopatologia" e "psicoterapia”.

Foram encontrados oito artigos, dois analisando como o psiquiatra era retratado em caricaturas 4,5 , três usando "cartoons" como ferramenta terapêutica ${ }^{6-8}$, dois estudos psicanalíticos ${ }^{9,10}$ e um estudo em psicologia social que discute as formas de representação do corpo masculino nas histórias em quadrinhos de super-heróis ${ }^{11}$. Nenhum artigo científico relacionando histórias em quadrinhos e psicopatologia foi localizado.

\section{Objetivos}

Identificar sintomas e síndromes psicopatológicas presentes em histórias em quadrinhos; verificar a frequência com que estas tratam de problemas de saúde mental e comparar se há diferença quanto ao tema entre as tiras nacionais e internacionais; avaliar as cenas selecionadas quanto a estereotipos, preconceitos e estigmas relevantes ao adoecer mental e elaborar rol de imagens que possa ser utilizado como recurso didático para tornar menos árido o ensino de psicopatologia na graduação.

\section{Metodologia}

Foram coletadas as tirinhas dos jornais Folha de São Paulo e New York Times, do período de $1^{\circ}$ de fevereiro de 2007 a 31 de julho de 2007. Na Folha de São Paulo, foram estudados os autores brasileiros Adão Iturrusgarai, Arnaldo Angeli Filho, Caco Galhardo, Laerte Coutinho, Glauco Villas-Boas e Fernando Gonzalez e os americanos James Robert David e Richard Arthur Allan Browne. A coleta foi realizada na página da internet http://www1.folha.uol.com.br/fsp. Na página principal, há uma barra à esquerda para os quadrinhos da edição do dia. Nessa mesma área, há um elo com as edições anteriores, neste há um banco de dados dos últimos seis meses de publicações. O jornal Folha de São Paulo foi escolhido como universo desta pesquisa, pois é um dos jornais de maior tiragem do Brasil e privilegia autores brasileiros de histórias em quadrinhos. Tiras e cartoons do mesmo período publicados pelo New York Times também foram colecionados. Foram obtidos na página da internet www.gocomics.com. Foram os seguintes os autores lá publicados: Ben Sargent, Tom Toles, Jeff Danziger, Pat Oliphant, Gary Trudeau e Tony Auth.

As tiras foram classificadas nas seguintes categorias:

1. Crítica de costumes: referências críticas a política e a comportamentos e valores do cotidiano.

2. Crítica social: referência a problemas sociais.

3. Saúde em geral. Estas foram classificadas nos seguintes temas:

3.A. Saúde física e higiene: referência à saúde em geral, excluindo a saúde mental, que está inserida nas outras subcategorias.

3.B. Psiquiatria e saúde mental, divididas em:

a. Psicopatologia especial: referência a síndromes psicopatológicas.

b. Psicopatologia geral: referência a sintomas ou sinais psicopatológicos.

c. Psicoterapia.

d. Relacionamento familiar.

e. Relação conjugal: referência à relação entre membros de um casal.

f. Álcool e drogas.

g. Sexualidade, subdividida em:

g.1. Heterossexualidade.

g.2. Homossexualidade. g.3. Parafilias.

g.4. Disfunção sexual.

4. Outras e nonsense: quadrinhos que utilizam falas e ou cenas que não possuem sentido compartilhado com os leitores, ou que não podem ser classificadas nos indicadores acima, $\mathrm{e}$ piadas sobre o próprio cartunista.

A frequência das categorias foi comparada entre as histórias em quadrinho produzidas no Brasil e as americanas, utilizando o quiquadrado de Pearson. O nível de significância foi 0,05.

\section{Resultados}

Foram avaliadas 1.883 tirinhas. Entre elas, 1.022 de autores nacionais e 891 de autores americanos (293 publicados pela Folha de São Paulo e 568 pelo New York Times). A tabela 1 mostra a ocorrência e a porcentagem dos temas gerais abordados.

Tabela 1. Frequência e significância dos temas abordados nos quadrinhos brasileiros e norte-americanos

\begin{tabular}{l|c|c|c|c|c|c}
\hline $\begin{array}{l}\text { Catego- } \\
\text { rias gerais }\end{array}$ & $\begin{array}{c}\text { Frequência } \\
\text { nos autores } \\
\text { brasileiros }\end{array}$ & $\begin{array}{c}\text { Porcenta- } \\
\text { gem nos } \\
\text { autores } \\
\text { brasileiros } \\
\text { cia nos } \\
\text { autores } \\
\text { america- } \\
\text { nos }\end{array}$ & $\begin{array}{c}\text { Frequên- } \\
\text { gem nos } \\
\text { autores } \\
\text { america- } \\
\text { nos }\end{array}$ & $\begin{array}{c}\text { Qui-qua- } \\
\text { drado }\end{array}$ & $P$ \\
\hline Saúde & 770 & 49,7 & 204 & 13,6 & 499,23 & 0,0000 \\
\hline $\begin{array}{l}\text { Crítica } \\
\text { de cos- } \\
\text { tumes e } \\
\text { política }\end{array}$ & 376 & 24,2 & 879 & 58,8 & 376,83 & 0,0000 \\
\hline $\begin{array}{l}\text { Crítica } \\
\text { social }\end{array}$ & 312 & 20,1 & 409 & 27,3 & 2,82 & 0,09 \\
\hline $\begin{array}{l}\text { Non- } \\
\text { sense e } \\
\text { outros }\end{array}$ & 91 & 5,8 & 1 & 0,06 & 110,26 & 0,0000 \\
\hline \begin{tabular}{l} 
Total \\
\hline
\end{tabular} & 1.549 & & 1.493 & & & \\
\hline
\end{tabular}

Nas tiras americanas, predomina a crítica de costumes. As nacionais privilegiam a saúde e o nonsense. Não há diferença entre as histórias estrangeiras e brasileiras quando o tema é crítica social.

Das 770 tiras nacionais cujo tema foi saúde, a maioria abordou a psiquiatria ou saúde mental e sexualidade (Tabela 2). Nessa categoria, 171 tiras $(22,21 \%)$ abordaram heterossexualidade; $46(5,9 \%)$, homossexualidade; $11(1,4 \%)$, parafilias e $1(0,13 \%)$, disfunção sexual. Nas histórias americanas, sexualidade não foi abordada. O tema sexualidade foi abordado três vezes na tira Doonesbury e em nenhuma outra. Uma questionou a falta desse assunto na própria tira, outra abordou o direito dos homossexuais e ironizou a mudança de opinião de um político sobre esse assunto, e outra tratou do assédio sexual no exército. Os quadrinhos americanos abordaram saúde mental 34 vezes (qui-quadrado 108,$5 ; \mathrm{p}=0,0000$ ).

Poucas são as síndromes psiquiátricas ilustradas (psicoses, jogo patológico, fobias, transtorno de oposição e desafio, suicídio, transtorno obsessivo-compulsivo, transtornos de personalidade, transtorno de pânico, transtorno dos impulsos, ciúme patológico). Destaca-se uma série de 35 tiras de Angeli, sobre o personagem Meia-oito, satirizando a geração politizada da década de 1960. Nessa série, o personagem apresenta um quadro sugestivo de pseudologia fantástica, pois relata sua luta heroica contra a ditadura, mas os companheiros e contemporâneos não se recordam de sua participação. $\mathrm{O}$ quadro evolui para uma síndrome delirante e alucinatória. Uma série na tira Doonesbury no New York Times ilustra o transtorno por estresse pós-traumático e seu tratamento numa clínica de aconselhamento para veteranos de guerra. 
Tabela 2. Temas sobre saúde das histórias em quadrinhos nacionais

\begin{tabular}{l|c|c}
\hline \multicolumn{1}{c|}{ Categorias de saúde } & Frequência & $(\%)$ \\
\hline Sexualidade & 217 & 28,4 \\
\hline Psicopatologia geral & 182 & 23,64 \\
\hline Higiene e saúde física & 132 & 17,14 \\
\hline $\begin{array}{l}\text { Relacionamento } \\
\text { conjugal }\end{array}$ & 70 & 9,09 \\
\hline Álcool e drogas & 64 & 8,31 \\
\hline Tabagismo & 44 & 5,71 \\
\hline Psicoterapia & 31 & 4,03 \\
\hline Psicopatologia especial & 15 & 1,95 \\
\hline Relações familiares & 3 & 0,39 \\
\hline Total & 770 & 100,00 \\
\hline
\end{tabular}

Apesar das poucas síndromes descritas, os sinais e sintomas da psicopatologia geral são abundantes nas histórias brasileiras. Noventa e nove sintomas e sinais diferentes foram ilustrados: consciência (obnubilação, coma, síncope); consciência do eu (imagem corporal); atenção (atenção espontânea, atenção voluntária, distraibilidade, concentração); orientação (desorientação no espaço); memória (ecmnésia, memória delirante, amnésia); linguagem (prolixidade, linguagem pedante, detalhismo, solilóquio, gagueira); pensamento (pensamento mágico, obsessões de dúvida e contaminação, leitura da mente, pensamento automático negativo, pensamentos negativos, pensamento vago); juízo (ciúmes, ideias de grandeza, desconfiança, ideia prevalente, delírio do sósia); senso percepção (alucinações visuais e táteis, ilusão); conação (compulsão, abulia, cansaço, ambivalência); impulsividade (jogo, cleptomania, mentira patológica, suicídio, comportamento antissocial ou inadequado); instintos (fetichismo, travestismo, pedofilia, exibicionismo, obscenidades, desibinição, assédio sexual, masoquismo, sadismo, insônia, pesadelos, sonolência, hipersônia); psicomotricidade (inquietação, postura corporal bizarra, estereotipias, ecolalia); afetividade (irritação, puerilidade, apatia, taedium vitae, frieza de sentimentos, nojo, excitação, medo, tristeza, afeto inadequado, agressividade); humor (disforia, depressão, ansiedade e fobias); inteligência (pensamento concreto, testes psicológicos), outros sinais e sintomas (isolamento, prospecção, narcisismo, sensibilidade a ruído, estresse).

As histórias americanas abordaram os seguintes temas: intoxicação por álcool, uso de drogas, inteligência, amnésia, apatia, falta de concentração, sonolência, insônia, imagem corporal, baixa autoestima, desrealização, insegurança, abuso de cafeína, isolamento social, pensamento pobre, depressão, desorientação no tempo, síncope, sugestionabilidade, ecmnésia, irritação, alucinações visuais, compulsão de limpeza.

Apenas uma tira americana menciona uso de drogas e quatro referem-se a problemas relacionados ao álcool. Duas tratam de terapia e sete de aconselhamento para veteranos; 29 histórias abordam problemas de relacionamento conjugal ou familiar. Não houve diferença em relação ao tipo de sinais e sintomas abordados (quiquadrado $=0,30 ; \mathrm{p}=0,58)$.

Nos quadrinhos brasileiros, no tema saúde física, foram encontradas referências a: clínica médica (vômito, dor reumatismo, digestão, halitose, obesidade, infecção, câncer, indigestão, ruídos no estômago, febre, diabetes, enurese, soluços); dermatologia (acne, hirsutismo, alopecia, pediculose, escamas na pele, hiperidrose, micose, pediculose); clínica cirúrgica (cirurgia geral, proctologia, cirurgia plástica, próstata, mutilação, próteses, implante de seios, transplantes); otorrinolaringologia (surdez, mudez, gagueira); oftalmologia (miopia, presbiopia, amaurose); ginecologia e obstetrícia (transtorno pré-menstrual, polimastia, parto, amamentação); neurologia (marcha, parestesias); higiene e outros temas (hospital clínico e psiquiátrico, problemas de higiene, nutrição, dieta, parasitologia, deformidades físicas, odontologia, acidentes, exame físico, acupuntura, anatomia, medicamentos, clonagem). Um total de 55 temas diferentes foram abordados.

As histórias americanas que abordaram saúde física mencionaram poucos temas: células-tronco e falta de fundos adequados para os serviços destinados aos veteranos. Dezenove (32\%) trataram do tema obesidade. Entre as brasileiras, apenas uma abordou a obesidade (qui-quadrado 63,19; p =0,000) e os temas foram mais variados, totalizando 50 diferentes. Temas como: cegueira, tosse, miopia, hipermetropia, nutrição, exame médico, acupuntura, ferimentos, ortopedia, higiene, exercício físico, gripe, papilas gustativas, déficits motores, sedentarismo e dor (qui-quadrado $=6,51 ; \mathrm{p}=0,01$ ).

\section{Discussão}

Há diferenças entre as histórias em quadrinhos nacionais e estrangeiras quanto ao tema tratado. Nos quadrinhos brasileiros, predominam temas ligados à saúde e à crítica social; nos quadrinhos estrangeiros, a crítica aos costumes. A grande frequência de quadrinhos sobre miséria, favelas na periferia das cidades, violência, menor abandonado, uso de álcool e drogas e guerras sugerem que os temas abordados no Brasil são principalmente sobre os problemas locais da atualidade, embora existam algumas referências à guerra no Iraque. No New York Times, os problemas são também locais, mas há ênfase nos globais: pobreza, migração, genocídio no Sudão, violência urbana e aquecimento global foram alguns dos principais.

Aproximadamente, $70 \%$ do total das tirinhas brasileiras pesquisadas apresentam conteúdos sobre saúde. Isso pode refletir as preocupações do brasileiro e de nossos meios de comunicação. Diferentemente das tirinhas que possuem um tom crítico e irônico referente aos costumes e problemas sociais do país como a corrupção, a violência e o tráfico, as tiras sobre saúde usam do exagero, denunciando serviços de saúde de pouca qualidade.

Houve diferenças importantes na frequência do tema saúde física entre as tiras nacionais e americanas. As últimas concentram-se no tema obesidade e na falta de fundos adequados para a saúde dos veteranos de guerra, pouco abordando outros temas. A obesidade nos quadrinhos americanos está mais ligada a costumes, embora nos Estados Unidos seja assunto importante de saúde pública. Nas histórias brasileiras, o tema saúde física é bem mais variado, abordando principalmente problemas da pele, fraturas, vômitos, acidentes, deformidades físicas, problemas mais observáveis e associados ao cotidiano, costumes e hábitos sociais.

Pesquisas de opinião ${ }^{12-13}$ mostram que é grande a preocupação do brasileiro com seus problemas. Saúde sempre é mencionada em primeiro lugar, seguida por violência, desemprego, situação financeira. 96\% dos entrevistados afirmam ter utilizado algum serviço de saúde nos últimos dois anos. Para a população, os principais problemas da área da saúde que o governo deveria resolver são: falta de médicos, falta de medicamentos, demora no atendimento e falta de hospitais. O principal problema do Sistema Único de Saúde (SUS) são as filas de espera para obter consulta $(41,3 \%)$, fila de espera para exames $(14,4 \%)$ e fila de espera para internações $(7,5 \%)$. Nas Histórias em quadrinhos, a ambulância existe, o leito hospitalar existe, mas com equipamentos simples, o profissional de enfermagem existe, apesar de representado de modo estereotipado, com um chapéu e cruz. Mas as doenças, principalmente as crônicas, não são resolvidas. Malformações, mutilações, próteses, surdez e cegueira são mostradas com a pessoa acometida tendo que conseguir sobreviver por si só, sem ajuda da comunidade ou do estado.

As histórias em quadrinhos mostram que violência, pobreza e principalmente saúde são retratadas com grande frequência. A ocorrência elevada do tema saúde mental entre nossos cartunistas capta e denuncia o mal-estar e a falta de assistência que nossa população sofre. Apesar das reformas, a assistência psiquiátrica ainda é, infelizmente, de baixa qualidade. Em relação à psiquiatria, também é mais citado aquilo que encontra referência plausível no imaginário popular: brigas familiares, sexualidade, cenas de alcoolismo no bar, pessoas irritadas, senhoras tristes, isolamento social, o envelhecer com perda de memória. 
A preocupação com a aparência, fenômeno cultural contemporâneo, é mostrado por meio de temas relacionados a dermatologia, cirurgia plástica e implante de próteses nos seios.

A sexualidade é apresentada como independente do afeto. A mulher dadivosa no Carnaval, quadris largos, coxas largas e pouca roupa são representações comuns. A personagem D. Marta, de Glauco, que assedia seus colegas de trabalho, é punida, ridicularizada e rejeitada. Pelo menos não é despedida. Os mesmos temas, iniciativa feminina e sexualidade sem intimidade, estão presentes também nas histórias de Aline (Adão Iturrusgarai). Essa história mostra também a falta de cuidados preventivos básicos com a própria saúde, com a personagem buscando sua satisfação sexual em relacionamentos com muitos parceiros, mas sem cuidados e proteção nos seus relacionamentos. As histórias estrangeiras não abordam temas ligados à sexualidade. Tabus culturais e a grande liberdade editorial da Folha de São Paulo podem explicar a diferença.

As alterações da afetividade estão entre os principais sintomas psicopatológicos representados. Os personagens estão geralmente muito irritados ou tristes, mas há referências a frieza de sentimentos, disforia, ciúmes e outros sentimentos, emoções e alterações do humor. A irritação é explorada pelos autores pela técnica do exagero. Uma situação aparentemente normal, como colher flores no parque com a namorada, torna-se engraçada quando o personagem irrita-se drasticamente.

A depressão é sugerida quando os desenhistas retratam os personagens em posturas caídas; às vezes tem-se a impressão de que os personagens e o formato dos balões estão derretendo. Não raro, a irritação é ilustrada por personagens autocentrados e que não suportam ser contrariados. O transtorno pré-menstrual é tratado de modo estereotipado, descrito como associado a brigas conjugais e descontrole afetivo. Todos os autores brasileiros são homens e isso pode ser um viés.

A compreensão das histórias exige capacidade de pensamento abstrato e muitas situações humorísticas usam de alterações do pensamento, principalmente o pensamento concreto e o pensamento mágico. Esses sintomas aparecem, em larga escala nas tirinhas, por serem reflexo de consagrada técnica de humor. Essa busca a ruptura discursiva causada pela ambiguidade e o duplo sentido. Refletindo sobre a reação que resulta da ruptura discursiva, Xavier ${ }^{14}$ explica que o riso se dá a partir da intromissão de um pensamento de outra ordem lógica, que provoca uma súbita pane em nosso pensamento linear. Essa pane é capaz de levar-nos a um novo pensar ${ }^{14}$.

Alterações da consciência são muito representadas. Grande parte dessas tirinhas representa o sintoma obnubilação da consciência, uma vez que o uso de bebidas alcoólicas e drogas é bastante recorrente. Delirium representado por rebaixamento da consciência e alucinações visuais é sempre associado às drogas, e não a problemas clínicos, infecções ou alterações metabólicas. Síncopes são bastante comuns, ou por agressão, ou por quadros dissociativos decorrentes de grandes emoções. Cinco tirinhas explicitam o estado hipnótico, técnica pouco usada atualmente, mas presente no imaginário popular.

É interessante destacar que muitos dos personagens das tirinhas não são humanos. Encontra-se nesses personagens a acentuação do humor pelo estilo do ridículo. De acordo com Propp, a natureza que nos cerca não pode ser ridícula. Não existem florestas, campos, montanhas, mares, flores, ervas, gramíneas etc. que sejam ridículos. Há a possibilidade de o ridículo ser observável entre os animais e seres inanimados, especialmente se o fato ou ação que eles protagonizam nos remeterem a questões próprias do ser humano, ainda que indiretamente ${ }^{18}$. Essa estratégia discursiva causa aumento desproporcional e intencional das formas, fatos e atitudes. Produz-se o humor quando se retrata de modo excessivo sintomas como perda de noção do tempo, desinibição, obnubilação da consciência, abstinência e fissura causados pela ingestão excessiva de álcool.

A intoxicação alcoólica nas tirinhas ocorre porque o usuário está carente, busca inspiração, tenta afastar o sentimento de estresse e angústia, justifica as más escolhas passadas e futuras. Essas tirinhas são representadas geralmente em bares ou nos domicílios. É recorrente a alusão a festas e ao Carnaval. O alcoolista não é representado como doente. Algumas vezes é representado no bar com o humor triste ou disfórico, entretanto os autores recorrem a esse tema para relacionar o beber com "afogar as mágoas" e o usuário com o "vagabundo", também um estereótipo estigmatizante que não mostra o problema de saúde e as consequências para a sociedade. Estranho as histórias americanas não abordarem álcool e drogas, sabidamente grandes problemas políticos, criminais e de saúde pública. Nos Estados Unidos, a intoxicação alcoólica é uma metáfora para os excessivos gastos governamentais.

Drogas são virtualmente inexistentes nos quadrinhos americanos. No Brasil a representação do tabagismo, da dependência química e do alcoolismo não aborda a face patológica desses quadros. As consequências sociais e físicas não são relatadas, talvez por não serem engraçadas. Interessante que uma tira (Meia-oito) atribui à maconha problemas de memória. A síndrome apático-abúlica é ilustrada no personagem Orelha, de Angeli. A diferença entre os dois países pode ser pela maior tolerância do uso entre nós ${ }^{15}$.

As tirinhas sobre drogas retratam principalmente o uso da maconha e, em menor escala, da cola de sapateiro, cogumelos alucinógenos e substâncias injetáveis. Geralmente, os usuários são crianças; também são representados jovens, bichos e extraterrestres. Raramente, são adultos. Um personagem, Geraldão, deixa claro o uso múltiplo de drogas. Ele é retratado como de classe social média, mas geralmente o uso de drogas é ilustrado em contextos sociais de baixa renda. O personagem Faquinha do quadrinhista Glauco aparece em uma série de 15 tiras em que controla uma "boca de fumo".

O cerne do humor nessas tirinhas revela-se no cotidiano das favelas, em situações como a venda de drogas, o embate com a polícia, o menor abandonado. Segundo Eisner, especialista em quadrinhos, subverter a ordem autoritária, escancarar "verdades" escondidas, desmistificar o poder e a força, são alguns dos objetivos da aplicação dos exageros na obra de humor gráfico ${ }^{16}$.

Poucas histórias mostram a psicopatologia especial. Tal fato ocorre, pois mostrar uma síndrome requer conhecimento técnico e um espaço maior. O espaço limitado de uma tira, com três ou quatro quadros, dificulta uma reprodução adequada.

Também é interessante relatar que algumas histórias mostram o psiquiatra em ação ou abordam temas referentes à psicoterapia. Em sua maioria, representam o terapeuta atrás do divã. O psiquiatra é sempre do sexo masculino, de meia-idade, careca, com barba e óculos. Na imaginação popular, a psicanálise é realizada no divã e um diploma sempre está na parede. Nunca o psiquiatra parece prescrevendo um remédio, sempre realiza psicoterapia com um jargão psicanalítico. Outras formas de terapia hoje muito mais utilizadas não são representadas. O terapeuta é representado como no cinema, ou está entediado, ou é sádico, ou é incompetente, ou é mais doente que o paciente ou está apenas preocupado com as suas próprias finanças ${ }^{17,18}$. O autor Adão Iturrusgarai possui uma série de tiras relacionadas a questões culturalmente entendidas como traumáticas e, por consequência, necessitadas de terapia. A ênfase é em um único evento traumático. Fazer xixi na cama, influência da mãe, sexualidade do adolescente são, por exemplo, os estereótipos que predominam. Os eventos com potencial traumático psicológico refletem o medo de não respeitar as convenções sociais e de ser descoberto, passando vergonha. A terapia em geral é mal sucedida. Isso reflete a justa desconfiança nas cerca de 400 escolas de psicoterapia existentes, quase todas sem qualquer base científica e evidências de eficácia e segurança.

O cômico utiliza-se do tema da saúde para criar situações de humor no cotidiano. Ele não pretende representar fidedignamente uma síndrome psicopatológica, mas se utiliza de sintomas para criar situações inusitadas e estereótipos. Raramente, sintomas como compulsão, delírios, alucinações, ilusão, obnubilação da consciência são acompanhados de sofrimento pelo personagem.

Por outro lado, é possível notar conhecimentos específicos da área médica em algumas tiras com representações fidedignas de fobias, transtorno obsessivo-compulsivo, ciúme patológico e transtornos de personalidade. O suicídio é apresentado como uma opção intelectual, e não consequência de um transtorno mental. A pessoa á apresentada 
tomando uma decisão isolada, sem ser mostrada a repercussão que isso produz na família, amigos e sociedade.

O uso das histórias em quadrinhos na sala de aula pode facilitar ou chamar a atenção para um sinal ou sintoma e facilitar a posterior identificação dele, mas isso precisa ser avaliado por pesquisas. Entretanto, os quadrinhos usam com frequência o exagero, o estereótipo, a ambiguidade e o duplo sentido, e isso precisa ser assinalado ao aluno. $\mathrm{O}$ riso denuncia, mas pode não criar empatia e impedir o aluno de sentir e enxergar o mal-estar e o sofrimento do portador de um transtorno mental. Podem ser usados, mas com sensibilidade, cuidado e bom senso.

Hoje, os quadrinhos são mais aceitos e considerados uma forma de arte, mas no início eram vistos como fonte de desinformação e degradação de valores ${ }^{19,20}$. Mesmo em 1996, em simpósio sobre a Psicopatologia das Histórias em Quadrinhos, baseada em visão psicanalítica, foi considerado que os quadrinhos incitam a violência, o preconceito e a deploração dos valores da sociedade americana ${ }^{10}$. Não é o que foi observado nas histórias em quadrinhos analisadas. Estas denunciam e chamam atenção para os problemas de nossa sociedade, principalmente a saúde mental.

Este trabalho não contou com financiamento nem teve conflito de interesses.

\section{Referências}

1. Acevedo J. Como fazer história em quadrinhos. São Paulo: Global; 1990.

2. Silva N. Elementos para a análise das histórias em quadrinhos. INTERCOM - Sociedade Brasileira de Estudos Interdisciplinares da Comunicação. XXIV Congresso Brasileiro da Comunicação; Campo Grande /MS; 2001.

3. Dalgalarrondo P. Psicopatologia e semiologia dos transtornos mentais. Porto Alegre: Artmed; 2000.

4. Walter G. The psychiatrist in American cartoons. Acta Psycha Scand. 1992;82(2):167-72.

5. Fuller RE. Headshrinker. The psychiatrist in cartoons. Bull Menninger Clin. 1972;36(3):335-45.
6. Rubin L. Livesy H. Look up in the Sky! Using superheroes in play therapy. Int J Play Therapy. 2006;15(1):117-33.

7. Polivka J. Cartoon humor as an aid in therapy. Clin Gerontol. 1987;7(1):63-7.

8. Kennedy S. Leunig cartoons as therapeutic letters: crafting a viable therapeutic focus for change. Aust New Zeal J Fam Ther. 1995;16(4):190-200.

9. Rosen V. Variants of comic literature and their relationship to obsessivecompulsive phenomena. J American Psychoanal Assoc. 1963;11(10):70424.

10. Wearthan F, Legman G, Mosse HL, Elkisch P, Blumberg ML. The psychopathology of comic books. Am J Psychother. Belfer Education Center. 1996. Disponível em: http://www.highbeam.com>. Acessado em: 10 Mar 2010.

11. Beiras A, Lodetti A, Cabral AG, Toneli MJF, Raimundo P. Gênero e super-heróis: o traçado do corpo masculino pela norma. Psicol Soc. 2007;19(3):62-7.

12. Conselho Federal de Medicina. Atenção básica e perspectiva de atendimento igualitário na saúde. Medicina CFM. Ano XXIII, número 173, setembro/ outubro 2008, p. 14-5.

13. BRASIL. Conselho Nacional de Secretários de Saúde. A saúde na opinião dos brasileiros. Brasília: CONASS; 2003. Disponível em: www.conass.org. br/admin/arquivos/opiniao_brasileiros.pdf. Acessado em: 10 Mar 2010.

14. Xavier C. Aids é coisa séria - humor e saúde: análise dos cartuns. Hist Ciênc Saúde. 2001;8(1):193-21.

15. Mesquita EM, Nunes AJ, Cohen C. Avaliação das atitudes dos estudantes de medicina frente ao abuso de drogas por colegas do meio acadêmico. Rev Psiq Clín. 2008;35(Supl 1):8-12.

16. Eisner W. Quadrinhos e arte seqüencial. São Paulo: Martins Fontes; 1989.

17. Dubugras M, Mari J, Santos S. The image of psychiatrist in Academy Award winning films from 1991 to 2001. Rev Psiq Rio Gd Sul. 2007;29(1):100-9.

18. Oliva VHS, Zorzetto Filho D, Lotufo-Neto F. O retrato da psiquiatria pelos cinemas norte-americano e brasileiro. Rev Psiq Clín. 2010;37(2):89-95.

19. Cirne M, Moya A, D’assunção O, Aizen N. Literatura em quadrinhos no Brasil. Rio de Janeiro: Nova Fronteira; 2002.

20. Marry J. Sociologia das histórias em quadrinhos. Porto: Livraria Civilização; 2002. 